Published in final edited form as:

Arthritis Care Res (Hoboken). 2017 July ; 69(7): 952-958. doi:10.1002/acr.23085.

\title{
Perceived Community Environmental Factors Predict Risk of 5- year Participation Restriction among Older Adults with or at Risk of Knee Osteoarthritis: the MOST Study
}

\author{
Molly W. Vaughan, PhD, DPT, \\ Research Associate, Boston, University Sargent College of Health and Rehabilitation Sciences, \\ Boston, MA \\ David T. Felson, MD, MPH, \\ Professor of Medicine \& Epidemiology, Section Chief, Clinical Epidemiology Research \& Training \\ Unit, Director, Clinical Translational Science Award Training Program, Associate Director, Boston \\ University CTSI, Boston University School of Medicine, Boston, MA \\ Michael P. LaValley, PhD, \\ Professor, Department of Biostatistics, Boston University School of Public Health, Boston, MA \\ Gael I. Orsmond, PhD, \\ Associate Professor, Department of Occupational Therapy, Director, PhD in Rehabilitation \\ Sciences Program, Boston University Sargent College of Health and Rehabilitation Sciences, \\ Boston, MA
}

Jingbo Niu, DSc,

Senior Faculty, Department of Medicine - Nephrology, Baylor College of Medicine, Houston, TX

Cora E. Lewis, MD, MSPH,

Professor, Associate Director of Research, Division of Preventive Medicine, University of Alabama at Birmingham School of Medicine, Birmingham, AL

Neil A. Segal, MD, MS,

Professor and Faculty Physiatrist, Director of Clinical Research, Medical Director of Musculoskeletal Rehabilitation, Department of Rehabilitation Medicine, University of Kansas Medical Center, Kansas City, KS

Michael C. Nevitt, PhD, MPH, and

Professor, Department of Epidemiology \& Biostatistics, University of California San Francisco School of Medicine, San Francisco, CA

Julie J. Keysor, PhD, PT

Associate Professor, Department of Physical Therapy and Athletic Training, Boston University Sargent College of Health and Rehabilitation Sciences, Boston, MA

\section{Abstract}

Corresponding Author: Molly W. Vaughan, PhD, DPT, ENACT/Boston University, College of Health and Rehabilitation Sciences, Boston University, Boston, MA, mvaughan@bu.edu.

Conflict of interest statement: the authors have no financial disclosures and report no conflict of interest. 
Objective-Older adults with knee osteoarthritis (OA) who live in environments with mobility barriers may be at greater risk of developing participation restrictions, defined as difficulties in engagement in life situations. We investigated the risk of participation restriction over 5 years due to self-reported environmental features among older adults with knee OA.

Methods-Participants from the Multicenter Osteoarthritis Study (MOST) self-reported participation at baseline, 30 months, and 60 months using the Instrumental Role subscale of the Late Life Disability Index (LLDI). Data on self-reported environmental features were from the Home and Community Environment questionnaire administered in the MOST-Knee Pain \& Disability study, an ancillary study of MOST. The relative risks of developing participation restriction at 60 months, indicated by an LLDI score $<67.6 / 100$, due to reported high community mobility barriers and high transportation facilitators were calculated using robust Poisson regression, adjusting for covariates.

Results-Sixty-nine (27\%) of the 322 participants developed participation restriction by 60 months. Participants reporting high community mobility barriers at baseline had 1.8 times the risk [95\% CI: 1.2, 2.7] of participation restriction at 60 months, after adjusting for covariates. Selfreport of high transportation facilitators at baseline resulted in a reduced but statistically nonsignificant risk of participation restriction at 60 months [RR: 0.7, 95\% CI: 0.4, 1.1].

Conclusions-Higher perceived environmental barriers impact the risk of long-term participation restriction among older adults with or at risk of knee OA. Approaches aimed at reducing the development of participation restrictions in this population should consider decreasing environmental barriers.

Knee osteoarthritis (OA), a chronic disease that is characterized by joint degeneration, pain, swelling, and stiffness is the most prevalent type of arthritis and a leading cause of disability among older adults (1). Approximately 37\% of adults over age 60 in the United States have knee OA (2), with rates expected to rise over the upcoming decades due to rising rates of obesity and the aging of the population $(3,4)$. Almost $80 \%$ of people with OA have movement-related limitations, including difficulty climbing stairs, walking short distances, standing, and carrying objects (5). Disability, compromised economic status, and poor quality of life may ensue (6).

Participation restrictions, defined in the WHO's International Classification of Health, Functioning, \& Disability (ICF) as "problems an individual may have with involvement in life situations," are common among people with arthritis (6-9). Participation restrictions involve limitations in social activities, volunteering, working, or managing one's home (10) and are associated with poor health outcomes (11). Conversely, optimizing engagement in social and community activities is recognized as an essential goal of healthy aging and aging in place initiatives (12). It is estimated that approximately 23 million people are limited in participation in their usual activities due to arthritis (8).

Participation restriction is complex and may be best understood through a biopsychosocial lens, such as the ICF or a social ecological framework, which emphasize that a person's health condition interacts with disease-related, personal, environmental, and policy factors $(6,10,13,14)$. For example, while community mobility limitations (i.e., difficulties with navigating built and natural terrain) are associated with participation restriction among older 
adults and people with arthritis, (15) they do not explain all of the variance in participation among people with arthritis $(9,15)$. Some people with severe mobility limitations have high social and community participation, whereas others with minimal mobility limitations have more restricted participation. Other factors, such as increasing age $(9,16,17)$, pain $(18)$, body mass index (19), depressive symptoms $(7,15,20,21)$, and environmental barriers $(7,22,23)$, as well as lower education $(16,24)$ are associated with participation restrictions among people with arthritis and older adults.

The environment in which people live is related to health outcomes of older adults and people with arthritis $(11,22,25)$, including physical activity $(9,10)$, mobility $(26)$, and participation $(27,28)$. Physical environmental factors such as weather, places to sit in the community, and parks have been identified as important by people with OA $(29,30)$. Other environmental features, such as recreational facilities, access to a car or public transit, social support, and safety impact older adults' mobility and social participation (23). Likewise, neighborhoods which are highly walkable with good pedestrian infrastructure, safety, and greater access to benches, parks, and public transit have been linked in cross-sectional studies to increased physical activity of older adults (31) and older adults with functional limitations (32).

While there is evidence that modifiable features of the physical environment affect physical activity and other health outcomes of people with arthritis, only a few studies have measured their relationship to participation restriction specifically among people with arthritis, and all of these studies have been cross-sectional (28). Wilkie et al. (2007) found in a sample of older adults with knee pain that poor access to a car and poor access to public transit resulted in increased odds of participation restriction (11). Another study on older adults with one or more chronic conditions, including osteoarthritis or rheumatoid arthritis, found a significant association between neighborhood problems (e.g., traffic, crime) and satisfaction with participation (26).

These cross-sectional studies provide evidence that the physical environment in which people live may be related to their 'current' participation; however, they do not establish whether the impacts of environmental factors precede health outcomes. Longitudinal studies where baseline environmental factors are assessed and participants are followed over time for development of participation restriction avoid potential reversal of effects. The long-term impact of the environment on development of participation restriction, however, has not been widely studied among people with arthritis. Only one published longitudinal study examined the relationship between participation and accessibility of the home, transportation availability, and living near to friends or family among older adults. However, this study used a follow-up period of only one year and was not conducted among individuals with arthritis (26). Additionally, it did not assess environmental risk factors for the development of new participation restriction over time. In order to minimize participation restrictions among people with knee OA via community interventions, a better understanding of the long-term impact of modifiable physical environmental barriers is needed.

To address these gaps in the empirical evidence, we evaluated the relationship between greater self-reported community mobility barriers and transportation facilitators and risk of 
participation restriction 5 years later in older adults with or at risk of knee OA with functional limitations. In addition, we measured the relationship of perceived features of the environment with participation restriction over a shorter time period of 30 months to determine if trends were supportive of the longer-term outcome.

\section{Materials and Methods}

Data for these analyses are from the Multicenter Osteoarthritis Study (MOST), a longitudinal, prospective study aimed at identifying risk factors for knee OA (33), and the MOST-Knee Pain and Disability Study (MOST-KPAD), an ancillary study to MOST (22). Recruitment procedures and eligibility for MOST has been published elsewhere (34). In brief, community-dwelling individuals (age 50-79 at baseline) with radiographic knee or hip $\mathrm{OA}$ and knee or hip pain, or who were at risk of developing knee OA due to obesity, knee pain, or previous knee surgery or injury were recruited for the MOST study from Birmingham, Alabama and Iowa City, Iowa between 2003 and 2005 using mass mailings of study brochures and media campaigns. Exclusion criteria included: use of walker or personal assistance to ambulate, diagnosis of rheumatoid arthritis, ankylosing spondylitis, psoriatic arthritis, or reactive arthritis, bilateral total knee replacements, cancer in the past 3 years, or current use of dialysis. MOST-KPAD participants were recruited from the MOST cohort between 2004-2005 if they met the following criteria: i) age 65 or older, and ii) reported "any" difficulty on two or more of three items of the Western Ontario and McMaster Osteoarthritis Index (WOMAC) scale: (a) going upstairs, (b) rising from sitting, or (c) bending or squatting to the floor. Details on MOST-KPAD recruitment and sample are published elsewhere (22).

Participation was assessed via self-report with the Instrumental Role subscale of the Late Life Disability Index (LLDI) at each clinic visit in MOST. The LLDI has acceptable reliability, validity, and sensitivity to change in older adults (35-37) and assesses two dimensions of participation: frequency and limitation in performing life tasks. The Instrumental Role subscale assesses limitation in participating in 12 home and community activities (e.g., taking part in recreation, volunteering, visiting friends and family, taking part in social activities); each item is scored from 1-5 with total scores ranging from 12-60, with higher scores indicating greater participation (35). Scores were transformed to a 0-100 scale for interpretability and dichotomized using a previously established cut-point of $<67.6 / 100$ to define participation restriction (38). The cut-off score was obtained from a populationbased sample of older adults used to validate the scale and reflects people with moderate to severe limitations in activities (39). Participants meeting this definition of participation restriction at baseline were removed from the analyses.

The Home and Community Environment (HACE) questionnaire is a multi-item environmental measurement tool that was used to assess self-reported home and community environmental barriers and facilitators in the MOST-KPAD study at baseline. For the purpose of this study, baseline scores were used from two subscales of the HACE: the community mobility barriers and transportation facilitator subscales (Table 1). The HACE community mobility barriers subscale assesses the extent to which participants perceive their neighborhoods to have uneven sidewalks or walking areas, lack accessible parks and 
walking areas, lack safe parks/walking areas, lack places to sit and rest, and lack curb ramps. The transportation facilitators subscale assesses the perceived presence of public transportation that is nearby and accessible, accessible public parking, as well as to what extent participants have means of personal transportation (i.e., owning a car, able to drive). Response options for both scales are "a lot," "some," "not at all," and "don't know." "Don't know" responses were coded as missing. A barrier or facilitator was considered present if participants chose "a lot" or "some" for an environmental feature. Scores were summed and dichotomized into low community mobility barriers (zero or one barrier) or high barriers (two to five barriers). Scores from the transportation facilitator subscale of the HACE were summed and dichotomized into low (zero to three facilitators) or high (four or five facilitators) (22).

Baseline covariates used were age, sex, race, education, body mass index, depressive symptoms, study site, 20-meter walk time, and knee pain. These covariates were important to adjust for in our analyses due to their effect on participation as well as the impact they may have on participants' perception of their environment $(7,9,15-17,20,21,24)$. Education was dichotomized into high school education or less vs. some college or more. A score of 16 or more on the Center for Epidemiological Studies Depression (CES-D) scale indicated depressive symptoms. Site (Alabama or Iowa) was included as a covariate due to potential environmental differences that may exist between locations (40). Knee pain over the past 30 days was assessed using the Western Ontario and McMaster Osteoarthritis Index (WOMAC).

\section{Analysis}

We examined baseline covariates by conducting descriptive analyses. Bivariate analyses were conducted to identify differences in baseline covariates according to perceived environmental barriers or facilitators and study site using t-tests and chi-square tests for continuous and categorical variables, respectively. In our main analysis, the relative risk of participation restriction at 60 months due to high community mobility barriers and high transportation facilitators was calculated using a robust Poisson regression for binary data (41), adjusting for age, sex, race, education, body mass index (BMI), depressive symptoms, study site, 20-meter walk time, and knee pain. In a secondary analysis, the same approach was applied to the outcome of participation restriction by 30 months. As fewer than $15 \%$ of subjects were missing participation data at 60 months, our main analysis used the participants with complete data. However, we also performed multiple imputation sensitivity analyses to determine the likely impact of missing participation data on the observed associations between community mobility barriers and transportation facilitators with participation. In the sensitivity analyses, missing 60-month LLDI values were imputed based on previous LLDI values for the subject along with the study site, community mobility barriers or transportation facilitators (depending on which HACE subscale was used in the analysis), race, age, education, baseline BMI, depressive symptoms, walk time, and knee pain. We also conducted further sensitivity analyses to examine if there were significant differences in baseline covariates, participation scores, and environmental factors according to drop out or incomplete data at 60 months using chi-square or t-tests as appropriate. 
Statistical analyses were conducted using the GENMOD, MI and MIANALYZE procedures in SAS v. 9.3.

\section{Results}

Four hundred thirty-five participants were enrolled in MOST-KPAD at baseline. Of these, 113 participants had participation restrictions and were removed from the analyses at baseline. (Figure 1 for participant flowchart) The mean age of the sample $(\mathrm{N}=322)$ was 70 years and the mean baseline participation score was 80 [SD: 11.1], The majority of participants were white and female, and 34\% had achieved a high school education or less (Table 2). Sixty-eight percent of participants had knee OA. At baseline, the median number of community mobility barriers was 1.0 out of 5 (mean: 1.4) and the median number of transportation facilitators was 4 out of 5 (mean: 3.9) (Table 1 for reported percentages of environmental barriers and facilitators).

Bivariate analyses found that participants who reported high community mobility barriers $(\mathrm{n}=88,27 \%)$ at baseline were more likely to be older, live in Alabama, and have a high school education or less in comparison with people who reported low community mobility barriers. Participants who reported high transportation facilitators at baseline ( $\mathrm{n}=1 \mathrm{17}, 36 \%)$ were significantly more likely to live in Iowa and have some college education. When comparing baseline covariates by study site, Alabama had a higher percentage of non-whites and had significantly higher knee pain than the Iowa cohort. By 30 months, 56 (18\%) participants had developed participation restriction [mean: 79, SD: 13.3] and at 60 months, $69(27 \%)$ had developed participation restriction [mean: 76, SD: 13.3].

\section{Community Mobility Barriers}

At 60 months, persons reporting high community mobility barriers at baseline had 1.8 times the risk [95\% CI: 1.2, 2.7] of participation restriction after adjusting for covariates (Table 3). Knee pain was significant in the final adjusted model at 60 months [RR: 1.1, 95\% CI: 1.0, 1.2]. The multiple imputation sensitivity analysis for missing participation data at 60 months had a slightly attenuated risk [RR: $1.7,95 \% \mathrm{CI}: 1.1,2.5]$ for high community mobility barriers that remained statistically significant. Our secondary analysis of 30-month data found similar estimates of effect but findings were statistically non-significant after adjusting for covariates [RR: 1.5, 95\%) CI: 0.9, 2.5], A one-year increase in age [RR: 1.1, 95\% CI: 1.0, 1.2] and higher reported knee pain on the WOMAC [RR: 1.1, 95\% CI: 1.0, 1.2] were significant in the final, adjusted models at 30 months.

\section{Transportation Facilitators}

At 60 months, persons who reported high transportation facilitators at baseline had less participation restriction but the finding was not statistically significant [RR: 0.7, 95\%CI: 0.4 , 1.1] after adjusting for covariates. Knee pain was significant in the final model at 60 months [RR: 1.1, 95\%CI: 1.0, 1.2], The risk ratio for transportation facilitators remained the same in the multiple imputation sensitivity analysis. Similar but weaker associations for transportation facilitators were found at 30 months, [RR: 0.9, 95\%CI: 0.5, 1.5] again with 
both a one-year increase in age [RR: 1.1, 95\%CI: 1.0, 1.2] and higher reported knee pain [RR: 1.1, 95\%CI: 1.0, resulting in increased risk of participation restriction, respectively.

Sensitivity analyses comparing participants who were removed from the analyses (due to drop out or incomplete data) and those with complete data at 60 months on baseline covariates, participation scores, and environmental factors indicated significant differences between the groups in knee pain only. People who were removed from the analyses had significantly higher knee pain than those remaining at 60 months.

\section{Discussion}

This study measured the relationship between perceived environmental barriers and facilitators and the long-term risk of developing participation restriction among older adults with or at risk of knee OA. Participants who reported high community mobility barriers at baseline had nearly two times the risk of participation restriction at five years compared to people living in environments with perceived low barriers, even after adjusting for personal factors, knee pain, and function. Participants reporting high transportation facilitators at baseline had a suggestive trend of a reduced risk of participation restriction by about onethird after five years, although the relationship did not reach statistical significance. While a non-significant, weaker relationship between perceived environmental factors and participation outcomes was noted at 30 months, the trend followed what was more strongly observed at five years.

To our knowledge, this is the first study to link self-reported features of the physical environment prospectively to long-term development of participation restriction among people with knee OA. Previous longitudinal studies have found that the physical environment impacts mobility (42-44) or functional disability (45), with only one study assessing its relationship with participation over a one-year period (46). Similar to our study, these studies have highlighted that perceived environmental features, including safety, access to parks, accessibility, and public transit, significantly impact health outcomes of older adults. However, our study is the first to measure the relationship between greater perceived physical environmental barriers and the risk of developing participation restriction over time. Additionally, it is the first to do so in a cohort of older adults with or at risk of knee OA, who face physical limitations and symptoms different from a general aging population.

Our findings concur with current "aging in place" initiatives to decrease environmental barriers in cities in order to promote optimal living and health outcomes for older adults $(4,12)$ and suggest that these initiatives are important for people with knee OA. An agefriendly city, according to the World Health Organization, includes physical environmental facilitators similar to predictors in our study, such as accessibility, safety, and access to certain services (e.g., transportation, parks, recreational facilities) and promotes opportunities for participation and a better quality of life (12). Older adults spend more time in their neighborhoods and face changes in vision, hearing, and function over time which make them more vulnerable to environmental conditions (47). If participation restriction occurs, quality of life and social isolation may decline, resulting in institutionalization and an inability to "age in place." Modifying features of the physical environment, such as 
community mobility barriers, may offset this negative health outcome among older adults with or at risk of knee OA.

While our study did find a trend in the anticipated direction between perceived transportation facilitators and participation restriction, the finding was not as strong as others have reported $(11,46,48)$. This discrepancy in findings may be due to differences in measurement approaches or environmental differences. Using the HACE, we measured a combined effect of self-reported, neighborhood-level transportation factors (e.g., availability of public transit, adequate parking for people with disabilities, adapted public transportation for people with disabilities) and individual-level transportation factors (e.g., whether the participant has a car available and can drive). Other measurement approaches ascertain individual or neighborhood-level features separately, whereas the HACE was designed to measure these factors as one combined category (49). Furthermore, differences in geographical transportation needs could influence the findings. We did have a large number (20\%) of participants reporting they did not know whether public transit was available near their home, whereas $97-98 \%$ of people reported they had a car and were able to drive (Table 1), suggesting that both Iowa City and Birmingham, Alabama are highly car-dependent locations. Hence, there may have been limited variability in our transportation data.

Our study is not without limitations. First, there are inherent limitations to longitudinal study designs of the environment as neighborhood features are subject to change over time. In the present study, we were unable to assess environmental changes or whether residential relocation occurred among participants over the five years, which could result in substantial environmental changes. Previous research has cautioned that associations between environmental features and health outcomes, such as participation, may be due to selfselection bias, or the bias created from individuals choosing to live in specific neighborhoods based on their health-promoting characteristics, and not that neighborhoods lead to poor health. While the current study does not control for self-selection, there have been several studies identifying significant associations between the environment and health that persist even after controlling for residential self-selection (50). Third, our study assessed the environment via self-report, and this may present bias due to some people being more or less aware of their environment. While the HACE includes a "don't know" answer response option, it is possible that an environmental factor may not be present, resulting in over or under estimates of the factor. Though the use of perceived vs. objective environmental data has been debated, perceptions of one's environment may have a more direct link to participation behavior than objective measurement and previous studies using self-reported environmental data have also found significant associations with participation $(11,25,48)$. Fourth, there may be differences in environmental features by urban or rural locations that were not fully captured by controlling by site in the analyses. Fifth, while this study does measure the long-term risk of participation restriction due to certain features of the environment, it is not experimental and hence we could not measure causality. However, our longitudinal study found increasing risk of restrictions in participation over time, even after adjusting for confounders that may impact participation and one's perception of their environment. Future studies using quasi-experimental study designs are needed to replicate our findings. Finally, our study had a small sample size with a lack of geographic and racial diversity, reducing its generalizability to other populations. 
This study's finding that older adults with or at risk of knee OA are at greater risk of future restrictions in participation if they live in areas with greater environmental barriers (including less perceived access to parks, curb cuts, safety and perhaps transportation options), and that this risk increases over time, strengthens this field of study. Additionally, it adds to the empirical evidence asserting that participation is impacted not just by disease level factors of a person, such as knee pain and stiffness, or functional abilities, but also by the perceived environmental barriers of where a person with arthritis lives. As neighborhoods strive to become more supportive for older adults, many of whom have chronic conditions such as arthritis, reducing the number of physical environmental barriers may have positive long-term impacts on participation. More longitudinal and experimental studies are needed to replicate this study's findings.

\section{Acknowledgments}

This manuscript has been reviewed by MOST study investigators for its scientific content and data interpretation.

Funding

This work was supported by the National Institute on Disability, Independent Living, and Rehabilitation Research (HHS 90RT5009); the National Institute of Arthritis \& Musculoskeletal \& Skin Diseases MCRC (2P60AR047785-14); MOST is comprised of four cooperative grants (Felson - AG18820; Torner - AG18832, Lewis - AG18947, and Nevitt - AG19069) funded by the National Institutes of Health, a branch of the Department of Health and Human Services, and conducted by MOST study investigators. This manuscript was prepared using MOST data and does not necessarily reflect the opinions or views of MOST investigators.

\section{References}

1. Guccione AA, Felson DT, Anderson JJ, et al. The effects of specific medical conditions on the functional limitations of elders in the Framingham Study. Am J Public Health. 1994; 84(3):351358. [PubMed: 8129049]

2. Dillon CF, Rasch EK, Gu Q, Hirsch R. Prevalence of knee osteoarthritis in the United States: arthritis data from the Third National Health and Nutrition Examination Survey 1991-94. J Rheumatol. 2006; 33(11):2271-2279. [PubMed: 17013996]

3. Deshpande BR, Katz JN, Solomon DH, et al. The number of persons with symptomatic knee osteoarthritis in the United States: Impact of race/ethnicity, age, sex, and obesity. Arthritis Care Res. Mar.2016 :n/a-n/a. DOI: 10.1002/acr.22897

4. Palazzo C, Nguyen C, Lefevre-Colau M-M, Rannou F, Poiraudeau S. Risk factors and burden of osteoarthritis. Ann Phys Rehabil Med. 2016; 59(3):134-138. DOI: 10.1016/j.rehab.2016.01.006 [PubMed: 26904959]

5. Centers for Disease Control and Prevention. [July 10, 2014] Arthritis national statistics. Arthritis CDC. http://www.cdc.gov/arthritis/datastatistics.htm

6. Carr AJ. Beyond disability: measuring the social and personal consequences of osteoarthritis. Osteoarthritis Cartilage. 1999; 7(2):230-238. DOI: 10.1053/joca.1998.0154 [PubMed: 10222222]

7. Theis KA, Murphy L, Hootman JM, Wilkie R. Social participation restriction among US adults with arthritis: a population-based study using the International Classification of Functioning, Disability and Health. Arthritis Care Res. 2013; 65(7):1059-1069.

8. Barbour KE, Helmick CG, Theis KA, Murphy LB, Hootman JM, Brady TJ, Cheng YJ. Prevalence of doctor-diagnosed arthritis and arthritis-attributable activity limitation-United States, 2010-2012. MMWR. 2013; 62(44):869-873. [PubMed: 24196662]

9. Gignac MA, Backman CL, Davis AM, Lacaille D, Cao X, Badley EM. Social role participation and the life course in healthy adults and individuals with osteoarthritis: are we overlooking the impact on the middle-aged? Soc Sci Med 1982. 2013; 81:87-93. 
10. World Health Organization. International classification of functioning, disability, and health. Geneva: World Health Organization 2001; 2001.

11. Wilkie R, Peat G, Thomas E, Croft P. Factors associated with restricted mobility outside the home in community-dwelling adults ages fifty years and older with knee pain: An example of use of the international classification of functioning to investigate participation restriction. Arthritis RheumArthritis Care Res. 2007; 57(8):1381-1389.

12. Plouffe L, Kalache A. Towards Global Age-Friendly Cities: Determining Urban Features that Promote Active Aging. J Urban Health Bull N Y Acad Med. 2010; 87(5):733-739. DOI: 10.1007/ s11524-010-9466-0

13. Devereux PG, Bullock CC, Gibb ZG, Himler H. Social-ecological influences on interpersonal support in people with physical disability. Disabil Health J. 2015; 8(4):564-572. DOI: 10.1016/ j.dhjo.2015.05.002 [PubMed: 26123858]

14. Peters TJ, Sanders C, Dieppe P, Donovan J. Factors associated with change in pain and disability over time: a community-based prospective observational study of hip and knee osteoarthritis. Br J Gen Pract. 2005; 55(512):205-211. [PubMed: 15808036]

15. Machado GP, Gignac MA, Badley EM. Participation restrictions among older adults with osteoarthritis: a mediated model of physical symptoms, activity limitations, and depression. Arthritis Rheum. 2008; 59(1):129-135. [PubMed: 18163415]

16. Bowling A, Stafford M. How do objective and subjective assessments of neighbourhood influence social and physical functioning in older age? Findings from a British survey of ageing. Soc Sci Med. 2007; 64(12):2533-2549. [PubMed: 17433509]

17. Wilkie R, Peat G, Thomas E, Croft P. The prevalence of person-perceived participation restriction in community-dwelling older adults. Qual Life Res. 2006; 15(9):1471-1479. DOI: 10.1007/ s11136-006-0017-9 [PubMed: 17009086]

18. Wilkie R, Blagojevic-Bucknall M, Jordan KP, Lacey R, McBeth J. Reasons Why Multimorbidity Increases the Risk of Participation Restriction in Older Adults With Lower Extremity Osteoarthritis: A Prospective Cohort Study in Primary Care. Arthritis Care Res. 2013; 65(6):910919. DOI: 10.1002/acr.21918

19. Batsis JA, Zbehlik AJ, Barre LK, Bynum JPW, Pidgeon D, Bartels SJ. Impact of obesity on disability, function, and physical activity: data from the Osteoarthritis Initiative. Scand J Rheumatol. 2015; 44(6):495-502. DOI: 10.3109/03009742.2015.1021376 [PubMed: 26083472]

20. Wilkie R, Blagojevic-Bucknall M, Jordan KP, Lacey R, McBeth J. Reasons Why Multimorbidity Increases the Risk of Participation Restriction in Older Adults With Lower Extremity Osteoarthritis: A Prospective Cohort Study in Primary Care. Arthritis Care Res. 2013; 65(6):910919. DOI: $10.1002 /$ acr.21918

21. Thorpe RJ, Wynn AJ, Walker JL, et al. Relationship Between Chronic Conditions and Disability in African American Men and Women. J Natl Med Assoc. 2016; 108(1):90-98. DOI: 10.1016/j.jnma. 2015.12.012 [PubMed: 26928493]

22. Keysor JJ, Jette AM, LaValley MP, et al. Community Environmental Factors Are Associated With Disability in Older Adults With Functional Limitations: The MOST Study. J Gerontol Ser -Biol Sci Med Sci. 2010; 65(4):393-399.

23. Levasseur M, Généreux M, Bruneau J-F, et al. Importance of proximity to resources, social support, transportation and neighborhood security for mobility and social participation in older adults: results from a scoping study. BMC Public Health. 2015; 15(1):503.doi: 10.1186/ s12889-015-1824-0 [PubMed: 26002342]

24. Cleveland RJ, Luong M-LN, Knight JB, et al. Independent associations of socioeconomic factors with disability and pain in adults with knee osteoarthritis. BMC Musculoskelet Disord. 2013; 14(1):297.doi: 10.1186/1471-2474-14-297 [PubMed: 24134116]

25. Hand C, Law M, Hanna S, Elliott S, McColl MA. Neighbourhood influences on participation in activities among older adults with chronic health conditions. Health Place. 2012; 18(4):869-876. [PubMed: 22469501]

26. Hand C, Law M, Hanna S, Elliott S, McColl MA. Neighbourhood influences on participation in activities among older adults with chronic health conditions. Health Place. 2012; 18(4):869-876. DOI: 10.1016/j.healthplace.2012.03.004 [PubMed: 22469501] 
27. Theis KA, Furner SE. Shut-In? Impact of Chronic Conditions on Community Participation Restriction among Older Adults. J Aging Res. 2011; 2011doi: 10.4061/2011/759158

28. Vaughan M, LaValley MP, AlHeresh R, Keysor JJ. Which Features of the Environment Impact Community Participation of Older Adults? A Systematic Review and Meta-Analysis. J Aging Health. Nov.2015 :0898264315614008.doi: 10.1177/0898264315614008

29. van der Pas S, Schaap LA, Castell MV, et al. Availability and use of neighborhood resources by older people with osteoarthritis: Results from the European Project on OSteoArthritis. Health Place. 2016; 37:1-7. DOI: 10.1016/j.healthplace.2015.10.006 [PubMed: 26699445]

30. Timmermans EJ, van der Pas S, Schaap LA, et al. Self-perceived weather sensitivity and joint pain in older people with osteoarthritis in six European countries: results from the European Project on OSteoArthritis (EPOSA). BMC Musculoskelet Disord. 2014; 15:66.doi: 10.1186/1471-2474-15-66 [PubMed: 24597710]

31. Moran M, Van Cauwenberg J, Hercky-Linnewiel R, Cerin E, Deforche B, Plaut P. Understanding the relationships between the physical environment and physical activity in older adults: a systematic review of qualitative studies. Int J Behav Nutr Phys Act. 2014; 11:79.doi: 10.1186/1479-5868-11-79 [PubMed: 25034246]

32. Van Holle V, Van Cauwenberg J, Gheysen F, et al. The Association between Belgian Older Adults' Physical Functioning and Physical Activity: What Is the Moderating Role of the Physical Environment? PLoS ONE. 2016; 11(2):e0148398.doi: 10.1371/journal.pone.0148398 [PubMed: 26872017]

33. Felson DT, Niu J, Guermazi A, et al. Correlation of the development of knee pain with enlarging bone marrow lesions on magnetic resonance imaging. Arthritis Rheum. 2007; 56(9):2986-2992. DOI: 10.1002/art.22851 [PubMed: 17763427]

34. Segal NA, Nevitt MC, Gross KD, et al. The Multicenter Osteoarthritis Study: Opportunities for Rehabilitation Research. PM\&R. 2013; 5(8):647-654. DOI: 10.1016/j.pmrj.2013.04.014 [PubMed: 23953013]

35. Jette AM, Haley SM, Coster WJ, et al. Late Life Function and Disability Instrument I. Development and Evaluation of the Disability Component. J Gerontol A Biol Sci Med Sci. 2002; 574:M209-M216. DOI: 10.1093/gerona/57.4.M209

36. Beauchamp MK, Jette AM, Ward RE, et al. Predictive Validity and Responsiveness of PatientReported and Performance-Based Measures of Function in the Boston RISE Study. J Gerontol A Biol Sci Med Sci. Dec.2014 glu227. doi: 10.1093/gerona/glu227

37. Beauchamp MK, Schmidt CT, Pedersen MM, Bean JF, Jette AM. Psychometric properties of the Late-Life Function and Disability Instrument: a systematic review. BMC Geriatr. 2014; 14:12.doi: 10.1186/1471-2318-14-12 [PubMed: 24476510]

38. Maxwell JL, Keysor JJ, Niu J, et al. Participation Following Knee Replacement: The MOST Cohort Study. Phys Ther. 2013; 93(11):1467-1474. DOI: 10.2522/ptj.20130109 [PubMed: 23813082]

39. Jette, AM., Haley, SM., Kooyoomjian, JT. Late-Life FDI Manual. Boston University, Roybal Center for Enhancement of Late-Life Function; 2002.

40. White DK, Keysor JJ, Neogi T, et al. When it hurts, a positive attitude may help: association of positive affect with daily walking in knee osteoarthritis. Results from a multicenter longitudinal cohort study. Arthritis Care Res. 2012; 64(9):1312-1319. DOI: 10.1002/acr.21694

41. Chen W, Shi J, Qian L, Azen SP. Comparison of robustness to outliers between robust poisson models and log-binomial models when estimating relative risks for common binary outcomes: a simulation study. BMC Med Res Methodol. 2014; 14:82.doi: 10.1186/1471-2288-14-82 [PubMed: 24965498]

42. Clarke P, Ailshire JA, Lantz P. Urban built environments and trajectories of mobility disability: Findings from a national sample of community-dwelling American adults (1986-2001). Soc Sci Med. 2009; 69(6):964-970. DOI: 10.1016/j.socscimed.2009.06.041 [PubMed: 19643522]

43. Eronen J, Bonsdorff M von, Rantakokko M, Rantanen T. Environmental facilitators for outdoor walking and development of walking difficulty in community-dwelling older adults. Eur J Ageing. 2013; 11(1):67-75. DOI: 10.1007/s10433-013-0283-7 
44. Gauvin L, Richard L, Kestens Y, et al. Living in a Well-Serviced Urban Area Is Associated With Maintenance of Frequent Walking Among Seniors in the VoisiNuAge Study. J Gerontol B Psychol Sci Soc Sci. 2012; 67B(1):76-88. DOI: 10.1093/geronb/gbrl34

45. McLaughlin D, Leung J, Pachana N, Flicker L, Hankey G, Dobson A. Social support and subsequent disability: it is not the size of your network that counts. Age Ageing. 2012; 41(5):674677. [PubMed: 22454132]

46. Haak M, Fange A, Horstmann V, Iwarsson S. Two dimensions of participation in very old age and their relations to home and neighborhood environments. Am J Occup Ther. 2008; 62(1):77-86. [PubMed: 18254434]

47. Glass TA, Balfour J. Neighborhoods, aging, and functional limitations. Neighborhoods and Health. 2003; 1:303-334.

48. Richard L, Gauvin L, Gosselin C, Laforest S. Staying connected: neighbourhood correlates of social participation among older adults living in an urban environment in Montreal, Quebec. Health Promot Int. 2009; 24(1):46-57. [PubMed: 19098293]

49. White DK, Jette AM, Felson DT, et al. Are features of the neighborhood environment associated with disability in older adults? Disabil Rehabil. 2010; 32(8):639-645. DOI: 10.3109/09638280903254547 [PubMed: 20205576]

50. Xinyu, Cao, Mokhtarian, PL., Handy, SL. Examining the Impacts of Residential Self-Selection on Travel Behaviour: A Focus on Empirical Findings. Transp Rev. 2009; 29(3):359-395. DOI: 10.1080/01441640802539195 


\section{Significance and Innovation}

- $\quad$ This is the first study to find a relationship between perceived community mobility and transportation features and the long-term risk of developing participation restriction among older adults with or at risk of knee osteoarthritis.

- $\quad$ Older adults with or at risk of knee osteoarthritis with perceived high community mobility barriers show nearly twice the risk of developing participation restriction over five years.

- $\quad$ This study provides empirical evidence to a growing body of literature linking perceived environmental features to participation outcomes and healthy aging among older adults and people with arthritis. 

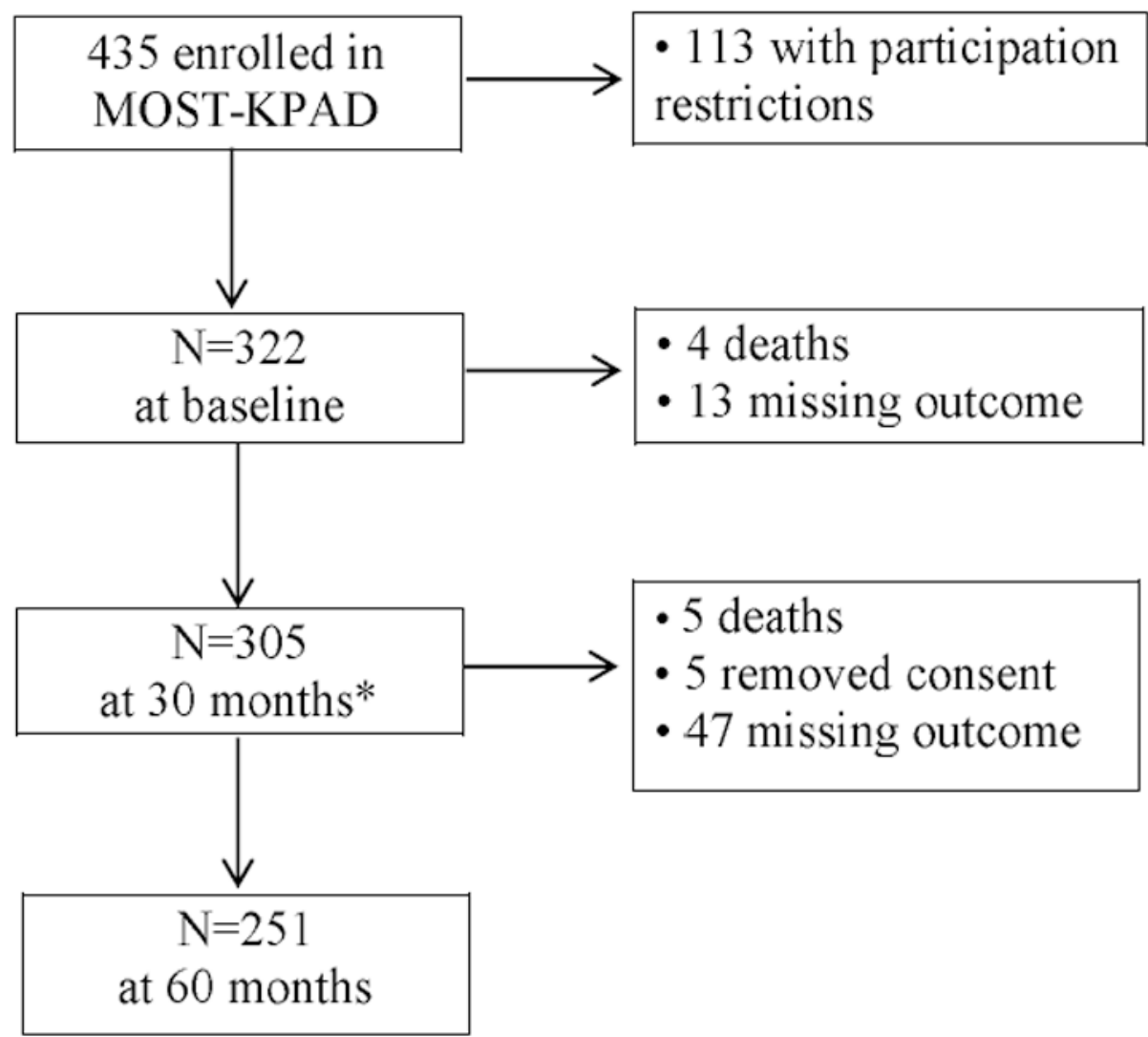

Figure 1.

Participant flowchart

*Note: 3 participants missing 30 months outcome assessment were present at 60 months outcome assessment 


\section{Table 1}

Perceived community mobility barriers and facilitators $(\mathrm{N}=322)$

\begin{tabular}{|c|c|c|}
\hline Home and Community Environment (HACE) Subscale & $\begin{array}{c}\text { n }(\%) \text { with } \\
\text { Barrier/Facilitator } \\
\text { Present }\end{array}$ & $\begin{array}{c}\text { n }(\%) \text { with Don't } \\
\text { Know or Missing } \\
\text { Values }\end{array}$ \\
\hline \multicolumn{3}{|l|}{ Community Mobility Barriers } \\
\hline Uneven sidewalks or other walking areas (a lot/some) & $261(83.1)$ & $8(2.5)$ \\
\hline No parks/walking areas that are easy to get to and easy to use & $34(10.6)$ & $2(0.6)$ \\
\hline No safe parks/walking areas & $28(9.2)$ & $16(5.0)$ \\
\hline No places to sit/rest at bus stops, in parks, or in other places where people walk & $63(21.0)$ & $22(6.8)$ \\
\hline No curbs with curb cuts & $56(18.3)$ & $16(5.0)$ \\
\hline \multicolumn{3}{|l|}{ Transportation Facilitators } \\
\hline Public transportation that is close to your home (a lot/some) & $186(71.0)$ & $60(18.6)$ \\
\hline $\begin{array}{l}\text { Public transportation with adaptations for people who are limited in their daily activities (a lot/ } \\
\text { some) }\end{array}$ & $301(94.4)$ & $3(0.9)$ \\
\hline Handicap parking (a lot/some) & $144(47.1)$ & $16(5.0)$ \\
\hline Have a car available to you at your home (yes) & $318(99.1)$ & $1(0.3)$ \\
\hline Able to drive (yes) & $315(98.1)$ & $1(0.3)$ \\
\hline
\end{tabular}




\section{Table 2}

Baseline characteristics $(\mathrm{N}=322)$

\begin{tabular}{ll}
\hline Sex, $\mathrm{n}(\%)$ & \\
Female & $223(69.3)$ \\
Age, mean (SD) & $70.3(3.9)$ \\
Race, $\mathrm{n}(\%)$ & \\
$\quad$ White or Caucasian & $302(93.8)$ \\
$\quad$ Black or African American & $20(6.2)$ \\
Education, $\mathrm{n}(\%)$ & \\
$\quad$ High school education or less & $108(33.5)$ \\
$\quad$ Some college or more & $214(66.5)$ \\
Site, $\mathrm{n}(\%)$ & \\
$\quad$ Birmingham, Alabama & $154(47.8)$ \\
Iowa City, Iowa & $168(52.2)$ \\
Depressive symptoms, $\mathrm{n}(\%)$ & $23(7.1)$ \\
Body mass index, mean (SD) & $29.9(5.3)$ \\
Knee osteoarthritis, n (\%) & $220(68.3)$ \\
WOMAC ${ }^{*}$ knee pain, mean (SD) (range: 0-20) & $5.3(3.4)$ \\
20-meter timed walk (secs), mean (SD) & $17.3(2.6)$ \\
Participation (Late Life Disability Index, Instrumental Role subscale), mean (SD) (range: 0-100) & $80.3(11.0)$ \\
Community mobility barriers, median (mean) (range: 0-5) & $1.0(1.4)$ \\
Transportation facilitators, median (mean) (range: 0-5) & $4.0(3.9)$ \\
\hline * & \\
WOMAC: Western Ontario and McMaster Osteoarthritis Index & \\
& \\
\hline
\end{tabular}


Table 3

Risk ratio $(\mathrm{RR})$ of participation restriction at 60 months $(\mathrm{N}=251)$

\begin{tabular}{|c|c|c|c|}
\hline & Subjects n (\%) & Crude RR [95\% CI] p-value & Multivariable Adjusted $\mathbf{R R}^{*}[95 \% \mathrm{CI}]$ p-value \\
\hline \multicolumn{4}{|c|}{ Community mobility barriers } \\
\hline High & $88(27.3)$ & $2.0[1.3,2.9] p<.001$ & $1.8[1.2,2.7] p<.01$ \\
\hline Low & $234(72.7)$ & (ref) & (ref) \\
\hline \multicolumn{4}{|c|}{ Transportation facilitators } \\
\hline High & $205(63.7)$ & $0.6[0.4,0.9] p<.01$ & $0.7[0.4,1.1] \mathrm{p}=.08$ \\
\hline Low & $117(36.3)$ & (ref) & (ref) \\
\hline
\end{tabular}

Arthritis Care Res (Hoboken). Author manuscript; available in PMC 2018 July 01. 